\title{
Misión del laico en el testimonio del Nuevo Testamento y en las últimas congregaciones generales de la Compañía de Jesús*
}

\author{
Xavier Alegre \\ Facultad de Teología de Cataluña, España \\ Centro Monseñor Romero, El Salvador
}

\section{Misión del laico y de la laica en el Nuevo Testamento}

\subsection{Significado de la palabra "laico"}

La palabra "laico" debería significar, originalmente, y al margen del significado que este término adquirió, cuando el sacerdote consigue más relevancia en el cristianismo, "miembro del pueblo de Dios" - en griego, laós significa "pueblo". Y ser miembro del "pueblo de Dios" es la máxima dignidad de la que puede gozar un cristiano, a la cual accede por el bautismo. Pues el bautismo no

* El cambio de paradigma en la concepción del laico, que comienza con el Vaticano II, interpela a todas las congregaciones religiosas. En este artículo, muestro, a partir del Nuevo Testamento, la reacción de la Compañía de Jesús ante esta interpelación.

1. Cfr. H. Strathmann, Laós, ThWNT IV, 29-39; sobre el significado de "pueblo" en la Biblia, cfr. X. Léon-Dufour, Vocabulario de teología bíblica, pp. 657-664 (Barcelona, 1967). "En la cultura romana se utilizaba para designar a los miembros del pueblo llano, a los que pertenecían al 'pueblo', entendido como el conjunto de clases populares contrapuestas a los dirigentes y a los jefes. Laico es el miembro de la plebe (el no dirigente). En la cultura judía el término griego 'laico' aparece en las traducciones que se hacen de la Biblia al griego. Se emplea, a su vez, para designar lo profano, lo que no pertenece al ámbito de los levitas o sacerdotes, lo que no está consagrado a Dios"; $c f r$. J. A. Estrada, La identidad de los laicos. Ensayo de eclesiología, p. 112 (Madrid, ${ }^{2} 1990$ ). Pero esa no es la concepción propia del cristianismo neotestamentario, sino la que se desarrolló a medida que se fue resaltando el carácter "sacerdotal" de los ministros cristianos (cfr. ibid., pp. 109-152). Ese proceso fomentó 
solo lo libera de la esclavitud del pecado (Rom 6,6-7), sino que ayuda a revelar ${ }^{2}$, a tomar conciencia del hecho de que goza de la máxima dignidad a la que puede aspirar una persona: lo incorpora plenamente a Cristo ( $c f r$. Rom $6^{3}$ ) y lo constituye en hermano, hermana, de Jesús ( $c f r$. Rom 8,29; Heb 2,11-12.17), siendo, de pleno derecho, hijo, hija, de Dios ( $c f r .1$ Jn 3,1s; Rom 8,15-17.23; Ga 3,26; 4,5-7; Ef 1,5; Flm 2,15).

Ser hijo de Dios es algo que, en principio, ya sería válido para todo ser humano, puesto que ha sido creado por Dios a su imagen y semejanza ( $c f r$. Gn 1,27). Pero el bautismo nos invita a vivirlo y a celebrarlo mucho más profundamente, pues el sacramento nos hace tomar conciencia de ello y nos da la gracia para vivirlo plenamente.

Por lo tanto, dentro de la Iglesia no hay diferencias esenciales en cuanto a "dignidad", pues no hay dignidad más grande que la de ser hijo de Dios, tanto más cuanto que el Espíritu, que es don de Dios a toda persona bautizada, nos capacita para poder llamar a Dios con toda confianza, Abbá, papá querido ( $c f r$. Rom 8,14-17). Y, consecuentemente, nos revela que todas y todos somos, ante todo, hermanos ( $c f r$. Mt 23,8-9). En este sentido, se puede decir que de la vocación fundamental y propia del cristiano - dar testimonio de la filiación divina de todo ser humano y del amor previo, gratuito y universal de Dios- participamos todos por igual en la Iglesia, aunque tengamos funciones distintas, que, por otro lado, pueden llegar a ser muy significativas, y de liderazgo para el conjunto de la comunidad, como recuerda Pablo en 1 Corintios 12,27-30. Pero, en todo caso, aunque es verdad que las comunidades cristianas empiezan a estructurarse, para que, al crecer como comunidad y desaparecer sus fundadores, los apóstoles, puedan funcionar adecuadamente (cfr. 1 Tes 5,12; 1 Cor 16,15-16; 1 Pe 5,1-4). Sin embargo, en el Nuevo Testamento, esto jamás lleva a distinguir entre sacerdotes y laicos dentro de la comunidad cristiana ${ }^{4}$. Pues, como señala Estrada ${ }^{5}$ :

Todos [los miembros del pueblo de Dios] son sacerdotes, todos tienen la experiencia del Espíritu, todos tienen ya acceso directo a Dios en Cristo. Dios actúa en todos, también en los que no tienen funciones ministeriales o

un dualismo entre los miembros de la Iglesia, el cual es contrario de la teología del Nuevo Testamento.

2. Dios actúa poderosamente en el mundo revelando, tal como señala Pablo a propósito del evangelio, en Romanos 1,16-17; $c f r$. la interpretación de este texto, en X. Alegre, Carta a los Romanos, pp. 52-71 (Estella, 2012).

3. Como señala U. Wilckens, "[e]n el bautismo hemos sido unidos con Cristo de manera que el efecto expiatorio de su muerte se convierte en nuestra participación corporal en su destino; dicho más brevemente: de manera que el 'por nosotros' se convierte en el 'Con Cristo"'; en La carta a los Romanos (Rom 6-16), II, p. 38 (Salamanca, 1992).

4. Cfr. J. A. Estrada, La identidad, o. c., pp. 32-34.

5. Ibid., p. 36. 
jerárquicas. De ahí que todos deben contribuir a la misión y a la vitalidad de la comunidad, al margen de su status social, raza o sexo.

De hecho, Jesús, por sorprendente que ello pueda parecer, fue un "laico"', un miembro del pueblo de Dios sin más, y no un "sacerdote", según la concepción del Antiguo Testamento -o de las religiones del entorno. Pues en el Antiguo

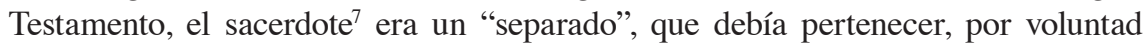
de Dios, a una tribu determinada, la de Leví, y, dentro de ella, a una familia, la de Aarón. Y el hecho de ser un "separado" "era significativo y le colocaba, en cierto modo, por encima de los demás miembros del pueblo de Dios, pues hacía de mediador entre Dios y su pueblo, por voluntad de Dios, que escogió para este servicio a la tribu de Leví y, más concretamente, a la familia de Aarón ( $c f r$. Ex 29).

Jesús, en cambio, era de la tribu de Judá. Y un profeta ( $c f r$. Mc 1,9-11). Por eso, nadie se atrevió durante su vida a darle el título de sacerdote - ni a él, ni a ninguno de sus discípulos, por cierto, incluso después de la resurrección. Y fue muy crítico con la institución sacerdotal judía y el Templo ( $c f r$. Mc 11,12-21). Solo la carta a los Hebreos, fijándose en que lo propio del sacerdote es hacer de puente entre Dios y los hombres, llamará a Jesús, iy solo a él!, el Sumo Sacerdote de la Nueva Alianza, por cuanto él, con su muerte y resurrección, realiza de modo definitivo, y único, la función de puente, de mediador, entre Dios y los hombres, pues, como recuerda san Pablo en 2 Corintios 5,17-21, en la cruz de Jesús, Dios estaba reconciliando al mundo (pecador) consigo.

Por otro lado, la manera como Jesús hace de puente entre Dios y los hombres no se asemeja a la de los sacerdotes de su tiempo", porque él, "el hombre que

6. "En el contexto judío, Jesús no es un sacerdote: ni por nacimiento, ni por estilo de vida, ni por sus actividades. Además, su muerte en la cruz es la antítesis de lo sagrado y de lo purificatorio, lo más contrario a la consagración sacerdotal" (ibid., pp. 17-18). Encontramos una buena presentación de la figura de Jesús en su relación con el sacerdocio, en A. Vanhoye, Sacerdotes antiguos, sacerdotes nuevos según el Nuevo Testamento, pp. 44-80 (Salamanca, 1984).

7. Sobre la figura del sacerdote en el Antiguo Testamento, $c f r$. A. Vanhoye, El mensaje de la carta a los Hebreos, pp. 12-14 (Estella, 1978); J. A. Estrada, La identidad, o. c., pp. 15-17; y la bibliografía citada en la p. 15, n. $^{\circ} 1$.

8. Como bien señala Estrada, "la función cultual-sacrificial es la prerrogativa sacerdotal por excelencia, y los sacerdotes constituyen un grupo segregado y sometido a reglas especiales. [...] Toda la estructura sacerdotal y cultual se basaba en la oposición de lo sagrado y lo profano y en la mediación ritual del sacerdocio entre ambos. La trascendencia y santidad de Dios obliga a establecer una separación estricta entre lo humano y lo divino, entre la vida profana cotidiana y el servicio religioso"; J. A. Estrada, $L a$ identidad, o. c., pp. 16s.

9. Este aspecto lo ha desarrollado muy bien A. Vanhoye en sus comentarios a la carta a los Hebreos. Cfr. Sacerdotes antiguos, o. c., pp. 85-246. También, y de manera resumida, en su Cuaderno Bíblico n. ${ }^{\circ}$ 19, El mensaje, o. c., pp. 15-18. Asimismo, 
vivió para los demás", no fomenta las mediaciones cultuales, que separaban a los sacerdotes de los demás, sino que está apasionado por realizar la voluntad de Dios, al que él, en su lengua materna, el arameo, llama Abbá, "papá querido" (cfr. Mc 14,36). Dicha voluntad consiste, para él, en hacer presente el reino-reinado de Dios en la tierra ( $c f r$. Mc 1,15), a fin de que todos los seres humanos puedan vivir humana y dignamente ${ }^{10}$. Pues Jesús sabe que lo que Dios quiere es, en formulación de san Ireneo, que "el ser humano viva". Esto es lo que se deduce de textos como Marcos 3,1-6, donde Jesús supedita el guardar el sábado a la búsqueda del bien para todo ser humano en necesidad.

Y eso implica, como supo reinterpretar muy bien Mons. Romero, "que el pobre viva", pues es el que tiene más amenazada la vida y, por otro lado, él es también el sacramento de la presencia de Jesús en la tierra (cfr. Mt 25,31-46). Por eso Lucas, cuando en los Hechos de los Apóstoles pone en boca de Pedro una frase lapidaria, que resume lo que fue la actuación de Jesús de Nazaret aquí en la tierra, dice simplemente: "Pasó por el mundo haciendo el bien y liberando a los que estaban oprimidos por el diablo" (Hch 10,38). Y esto no es algo exclusivo de los sacerdotes cristianos, sino de todo cristiano, también, por lo tanto, del que ahora denominamos "laico".

Y la manera como Jesús acercó a Dios a los hombres no fue a través de un sistema de separaciones, es decir, a través de unas personas (los sacerdotes), un lugar (el Templo) y unos tiempos (las fiestas) sagrados, "separados", sino a través de un sistema más bien de comuniones: come con los pecadores ( $c f r$. Mc 2,15-17; Lc 15,1-2; 19,1-10), toca a un leproso ( $c f r$. Mc 1,41), se deja tocar por una mujer

encontramos una reinterpretación breve del culto en la carta a los Hebreos, en J. A. Estrada, La identidad, o. c., pp. 19-23. Estrada, recogiendo bien lo que fue el servicio sacerdotal de Jesús (ibid., p. 20), señala que "[s]e da culto al Dios de la vida desde una vida gastada en servicio de los demás. La relación con Dios y la forma de relacionarse con los otros son las dos dimensiones de una misma actitud. Del mismo modo que Cristo ha sacrificado su vida, poniéndose al servicio del reino de Dios, así también deben vivir los cristianos. Esta es la nueva alianza, que no necesita otras privaciones (Heb 10,15-58) y es un compromiso de fe que no puede recaer en las viejas oblaciones y ofrendas (Heb 13,9-2 [sic]). La religión del Dios encarnado lleva consigo la mediación del prójimo como forma de relacionarse con Dios".

10. Se puede decir que toda la vida de Jesús fue, en cierto modo, "sacerdotal", en el sentido que esta palabra tiene desde Jesús. Así lo observa Estrada, a propósito de la vida de Jesús: "Es una vida sacerdotal que se expresa en una conducta y en el estilo con que afronta los acontecimientos, siendo la última cena la síntesis y plenitud de su entrega al Padre y a los hombres. Las múltiples alusiones sacerdotales que jalonan los evangelios nos hablan de una existencia consagrada a instaurar el reino de Dios, generando solidaridad entre los hombres y ofreciendo el regalo de un Dios bueno, especialmente con los marginados, los pobres y los pecadores"; J. A. Estrada, La identidad, o. c., p. 29. 
que tiene pérdidas de sangre ( $c f r$. Mc 5,25-34) o es notoriamente pecadora ( $c f r$. Lc 7,36-50). Y así les comunica la salvación de Dios (cfr. Mc 5,34; Lc 19,9-10).

Por eso Jesús, que en su actuación quiere comunicar la vida a todos, en especial, a aquellos que la tienen más amenazada y que están excluidos por la sociedad, opta prioritariamente por los pobres ( $c f r$. Mt 11,2-6; Lc 4,16-30). Y eso le costó la vida - como se la cuesta también a toda persona que toma en serio el proyecto de Jesús, un hecho que resulta fácil de comprender en El Salvador, pues basta con recordar a Mons. Romero, a los mártires de la UCA y a tantas personas, muchas de ellas anónimas, que pagaron con su vida el tomarse en serio el mensaje liberador de Jesús.

Llama la atención, en todo caso, que, aparte de Jesús, el Nuevo Testamento no aplica a nadie más el título de "sacerdote", sino solo al pueblo de Dios en su conjunto $^{11}$. Y lo hace así porque es todo el pueblo de Dios, en su conjunto, y, por lo tanto, la Iglesia, en cuanto tal y como laós (pueblo), la que recibe la misión, por parte de Jesús, de ser la mediadora entre Dios, que quiere la salvación de todo el mundo ( $c f r .1$ Tim 2,4), y el resto de la humanidad ( $c f r$. Ap 1,6; 5,9-10; 1 Pe 2,9; también Ex 19,6). Se trata de una humanidad que padece las consecuencias del pecado, que atenaza a la humanidad, pues se ha dejado esclavizar por los ídolos - hoy sobre todo el económico, incompatible con el Dios de Jesús ( $c f r$. Lc $16,13)$ - y no ha querido reconocer al Dios verdadero, con lo cual "en el pecado lleva la penitencia", pues el mal, la violencia y la injusticia dominan este mundo y provocan el sufrimiento innecesario de las mayorías empobrecidas, más aún, excluidas ( $c f r$. Rom 1,18-3,2012).

11. Y lo propio de este pueblo de Dios no son tanto las acciones cúlticas, cuanto el poner signos concretos de la cercanía del reino, curando a los enfermos, pero también luchando por la justicia y optando por los pobres. Por eso, Estrada, que se inspira en Pablo, señala que "[e]ste carácter sacerdotal y cultual de la comunidad cristiana se clarifica al reflexionar sobre la evangelización y la formación del pueblo de Dios. También aquí se trasponen los términos rituales y sagrados del Antiguo Testamento a un contexto vital: la liturgia cristiana es existencial y consiste en ofrecerse como hostia agradable a Dios (Rom 12,1-2). Pablo se designa a sí mismo como liturgo de Cristo entre los gentiles: su función sagrada es la de anunciar el evangelio para que la ofrenda de los paganos, consagrada por el Espíritu santo, le sea agradable (Rom 15,16). Asocia así estrechamente la predicación y el culto (Rom 1,9; 1 Cor 9,13-14), la misión y la identidad cristiana: la evangelización santifica a las naciones y las hace una ofrenda a Dios"; J. A. Estrada, La identidad, o. c., p. 39.

12. Sobre este texto, ver mi comentario en Carta a los Romanos, o. c., pp. 73-87; también "Los ídolos que deshumanizan al hombre (Rom 1,18-32)", en Memoria subversiva y esperanza para los pueblos crucificados, pp. 151-170 (Madrid, 2003). U. Wilckens, La carta a los Romanos, I, pp. 121-154 (Salamanca, 1989). 
En este sentido, Jesús dice a todos los miembros del pueblo de Dios que ellos están llamados a ser sal de la tierra y luz del mundo (Mt 5,13-16), ya que han recibido la misión, en cuanto pueblo de Dios, de transformar a fondo este mundo, trabajando para que Dios reine en él. Esto supone, en la tradición veterotestamentaria, procurar que ya no haya pobres en el mundo, porque todos comparten (cfr. Dt 15,4; Hch 4,42-47). Por eso, la misión que reciben los discípulos del Resucitado, cuando, según Mateo 28,16-20, se les aparece en una montaña de Galilea, no es que estructuren jerárquicamente a su Iglesia o que planifiquen el culto cristiano, sino que conviertan a todo el mundo en discípulo de Jesús, bautizándolos y enseñándolos a guardar todo lo que él les había enseñado, sobre todo, en Galilea, empezando por el sermón de la montaña (Mt 5-7).

Este formar parte del pueblo de Dios es algo previo y más fundamental que cualquiera de las funciones que una persona pueda desempeñar dentro de él. Por esto Pablo, que fue un buen discípulo de Jesús, comprendió y formuló muy bien la igualdad fundamental entre todos los miembros de la Iglesia (cfr. Ga 3,28). E insistió en que se formaba parte de la Iglesia, el cuerpo de Cristo, de la misma manera que se forma parte de un cuerpo, en el cual cada miembro tiene una función única e irrepetible y en el cual nadie puede situarse por encima de los otros miembros (cfr. 1 Cor 12).

Ningún cristiano o cristiana, por lo tanto, es mejor o peor que los demás por la función que desempeña en el cuerpo de la Iglesia. Simplemente, es distinto. Y la cooperación entre todos los miembros es algo esencial e irrenunciable para la buena marcha de la Iglesia ( $c f r .1$ Cor 3,5-15), sin que lo que uno haga lo coloque por encima de los demás. Todo lo contrario, el que quiera ser el primero debe ser el último y servidor de todos, a ejemplo de Jesús, que no vino a ser servido, sino a servir ( $c f r$. Mc 10,41-45), y que, para dar ejemplo, lavó los pies a sus discípulos (Jn 13,1-20).

Dicha colaboración es también fundamental para que la comunidad cristiana pueda desempeñar la misión que Dios le ha confiado, que consiste en transformar este mundo para que vayan apareciendo en él los "signos" del reino de Dios (Mt 10,7-8), tal como hizo Jesús (Lc 11,20), es decir, mostrar, como diríamos hoy, que otro mundo, un mundo fraternal y solidario, es posible y necesario. Estos signos son, en la visión neotestamentaria, como el anticipo y las arras del reinado definitivo de Dios, del cual el Espíritu ya ahora da testimonio dentro del cristiano, pues se trata de un reino que esperamos, como plenitud, solo al fin de los tiempos (cfr. Rm 8,18-30; 1 Cor 15,20-28).

Lo único que distingue positivamente a las personas cristianas, por consiguiente, no es tanto la función que desempeñan dentro de la Iglesia. Ser sacerdote, religioso, religiosa, laica, laico, es algo, eclesialmente, secundario. Lo importante es el amor con el cual realizan su función. Pues el don más grande que puede tener cualquier miembro, y conditio sine qua non para que lo que 
haga sea válido a los ojos de Dios, y eso no es propio de ningún grupo exclusivo dentro de la Iglesia, es su capacidad de amar ( $c f r .1$ Cor 13), de "vivir para los demás”, siguiendo a Jesús —esto es lo que está implícito en Marcos 8,34; cfr. Juan 13,34-35-, pues ello es la expresión del Espíritu Santo que lo anima ( $c f r$. Rom 8). $\mathrm{Y}$ vivir este amor con la mayor radicalidad posible, es lo esencial de toda vocación cristiana, pues como recuerda Jesús, según Mateo 12,7, citando a Oseas 6,6 (cfr. también Mt 9,13), lo que Dios quiere es misericordia y no sacrificio. Por eso para Jesús, tal como nos lo recuerdan Marcos, Mateo y Lucas (cfr. Mc 3,1-6 / Mt 12,9-14 / Lc 6,6-11), si una ley de Dios, por significativa que sea, entra en conflicto con el bien del ser humano, el bien del ser humano pasa por encima de todo.

Esto no debería sorprendernos, ni cuestionarnos, pues responde al talante de Jesús, que reflejan todos los evangelios, a pesar y en contra de la evolución que ha habido, luego, en la Iglesia, sobre todo, a partir de finales del siglo II, ya que, como señala Estrada ${ }^{13}$, los evangelios

... descalifican los comportamientos religiosos tradicionales, sus mediaciones absolutas (la ley y el culto veterotestamentario) y sus mediadores (sacerdotes y doctores), para poner el acento en un tipo de existencia humana que es la que permite conocer a Dios, relacionarse con él y vivir en comunión con la divinidad. La de Jesús, que ejemplifica y genera los comportamientos del hombre que vive según Dios.

Y es también desde esta perspectiva, más existencial que cúltica, como señala Estrada $^{14}$, que hay que interpretar la Última Cena de Jesús ( $c f r$. 1 Cor 11,23-25; Lc 22,15-20; Mc 14,22-25; Mt 26,26-29), celebrada por Jesús en una casa. Pues se trata de un ritual judío que celebra al Dios liberador, que da vida a su pueblo y que cobra ahora una singular dimensión. La última cena sintetiza lo que ha sido la vida de entrega de Jesús (su "proexistencia" en favor de los demás) y al mismo tiempo es un signo profético que proclama, anticipa y simboliza la entrega que se va a dar al Padre y a los hombres en los acontecimientos posteriores de la pasión ${ }^{15}$.

Por eso, Estrada tiene interés en subrayar lo propio de la eucaristía cristiana, aquello que revela en qué sentido se puede denominar "sacerdotal" la vida y muerte de Jesús y el peligro que comporta para el cristianismo volver a la ritualidad propia del judaísmo.

El pan que se rompe simboliza la vida que se da a los otros, y si no se está dispuesto a asumir ese significado, no se celebra la cena del Señor (a lo más, se degrada en una repetición del rito judío). La cruz añade así un duro significado

13. J. A. Estrada, La identidad, o. c., p. 30, sobre todo, pp. 53-79.

14. Ibid., pp. 25-31.

15. Ibid., pp. 26 s. 
a la ofrenda del pan y del vino, y la historia de Jesús se convierte en la clave de interpretación y de superación del ritual judío.

La tentación cristiana es volver a lo judío, hacer de la cena un rito en que se ofrece algo (aunque sea la muerte de Jesús) y no a alguien (una existencia, una forma de vivir); y hacer de ella un rito concluido (cuando en realidad es el memorial de una historia inconclusa que tiene que prolongarse en la vida de los participantes) y atemporal (cuando se refiere a un acontecimiento histórico que tiene que actualizarse en una forma concreta de vivir en los diversos momentos históricos $)^{16}$.

\subsection{Ser cristiano implica una vocación, una misión}

En principio, tal como muestran aquellos que en la Biblia son llamados a desempeñar una función en la historia de la salvación, toda persona cristiana, por el mero hecho de serlo, tiene una misión dentro de la Iglesia de cara al mundo entero ( $c f r$. Gn 12,3; Jer 20,7-9; Mc 1,16-18; Gal 1,15-17), pues gracias al bautismo, por el que hemos entrado a formar parte del pueblo de Dios, Cristo "ha hecho de nosotros un Reino de Sacerdotes" (cfr. Ap 1,6; también Ex 19,6; 1 Pe 2,9). Preguntémonos, pues, por qué la misión es algo inherente al ser de todo cristiano y cristiana.

Ser cristiano es siempre, y de entrada, un don gratuito recibido de Dios. Pues es por pura gracia, por puro amor gratuito de Dios, que cualquier persona es llamada por Dios a formar parte de su pueblo (cfr. Dt 7,6-8). Jamás la llamada de Dios es un mérito propio o un privilegio, que ponga por encima de los demás. Isaías ya lo había reconocido, al recibir la vocación de Dios (cfr. Is 6,1-13). Y Pablo es muy consciente de ello, cuando reconoce la total gratuidad de su llamado a ser apóstol, puesto que había sido un perseguidor de la Iglesia de Dios (cfr. 1 Cor 15,8-11). Y lo mismo vale para Pedro, quien en su primera vocación ya reconoce que es un pecador ( $c f r$. Lc 5,8-10). Asimismo, es consciente de ello cuando Jesús, después de pascua, vuelve a llamarlo y le confía que pastoree las ovejas de Jesús ( $c f r$. Jn 21,15-17 con Mc 14,66-71).

16. Ibid., p. 28. De todos modos, para comprender bien lo que acabamos de decir, conviene tener presente una observación de Estrada: "El cristianismo necesita, como toda religión, un conjunto de textos, ritos, símbolos y estructuras que le permitan subsistir y conservar su identidad específica y en las que se exprese el carácter trascendente y gratuito de la presencia de Dios en medio de la comunidad. Al servicio de estas necesidades surgen el canon de los escritos neotestamentarios, la regla de fe (el 'credo' o símbolo de la fe), las estructuras ministeriales y el conjunto de los sacramentos. Así como los símbolos más determinantes del cristianismo: la señal de la cruz o el domingo como memorial del día de la resurrección"; J. A. Estrada, $L a$ identidad, o. c., p. 62. 
La pregunta, entonces, es por qué Dios escoge un pueblo, un grupo de creyentes. ¿Qué pretende con ello?

La respuesta es doble. Por un lado, escoge un pueblo, Israel -y lo mismo vale luego para la Iglesia, que está enraizada en Israel, como subraya Pablo en Romanos 11,1-24-, para que realice un servicio fundamental al mundo entero: revelarle que el amor de Dios es siempre y esencialmente un amor gratuito y universal. Pablo ve revelada la gratuidad en la cruz de Cristo, tal como lo muestra claramente en Romanos 5,6-8, donde subraya:

Cuando todavía estábamos sin fuerzas, en el tiempo señalado, Cristo murió por los impíos - en verdad, apenas habrá quien muera por un justo; por un hombre de bien tal vez se atrevería uno a morir-, mas la prueba de que Dios nos ama es que Cristo, siendo nosotros todavía pecadores, murió por nosotros.

Y la universalidad la destaca en Romanos 11,32 ( $f f r$. 11,25-32), donde proclama, como conclusión de toda su reflexión teológica de 9-11: "Pues Dios encerró a todos los hombres en la rebeldía para usar con todos ellos la misericordia"'17.

Por eso, Dios no escoge un gran imperio o un pueblo poderoso para realizar su proyecto, sino a un emigrante primero (Abraham, cfr. Gn 12,1-3), y, luego, a un pueblo explotado y oprimido en Egipto (Israel, Ex 3). Esa gratuidad de la elección, que no se debe a los méritos de los que forman la Iglesia, es también lo que recuerda Pablo a la Iglesia de Corinto, cuando la invita a mirar cómo son sus miembros, que no se distinguen precisamente por ser la élite del mundo ( $c f r .1$ Cor 1,26-31).

Y, por el otro lado, Dios escoge un pueblo y una Iglesia, que retoma la antorcha que le ha dado Israel, pues esta sigue enraizada en él ( $c f r$. Rom 11,11-24), para, por su medio, hacer llegar a todos los pueblos de la tierra su amor liberador. Eso es lo que implica la idea de alianza en el Antiguo Testamento ( $c f r$. Dt 6,9-11) y la promesa de la tierra que mana leche y miel ( $c f r$. Dt 26,5-10 con 26,11-13). Ni la elección de Israel, ni la alianza, ni la promesa de la tierra son, simplemente, un privilegio a favor del pueblo elegido, ni están orientadas exclusivamente a Israel, como lo muestra la revelación de Dios a Isaías, cuando llega a llamar "mi pueblo" a Egipto, "la obra de mis manos" a Asur y "mi heredad" a Israel.

Aquel día habrá un altar de Yahvé en medio del país de Egipto y una estela de Yahvé junto a su frontera. Estará como señal y testimonio de Yahvé Sebaot en el país de Egipto. Cuando clamen a Yahvé a causa de los opresores, les enviará un libertador que los defenderá y librará. Será conocido Yahvé de Egipto, y

17. Puede verse cómo hay que interpretar la fórmula sorprendente "encerró", que en ningún caso supone manipulación por parte de Dios. Cfr. X. Alegre, Carta a los Romanos, o. c., pp. 294-296. 
conocerá Egipto a Yahvé aquel día, le servirán con sacrificio y ofrenda, harán votos a Yahvé y los cumplirán. Yahvé herirá a Egipto, pero al punto le curará. Se convertirán a Yahvé, y él será propicio y los curará. Aquel día habrá una calzada desde Egipto a Asiria, y Egipto servirá a Asur. Aquel día será Israel tercero con Egipto y Asur, objeto de bendición en medio de la tierra, pues le bendecirá Yahvé Sebaot diciendo: "Bendito sea mi pueblo Egipto, la obra de mis manos Asur, y mi heredad Israel" (19,19-25).

Y la misma idea la encontramos también detrás de un texto de Amós. “o son ustedes para mí como hijos de kusitas, oh, hijos de Israel? -oráculo de Yahvé. ¿No hice yo subir a Israel del país de Egipto, como a los filisteos de Kaftor y a los arameos de Quir?" (9,7; cfr. también Jon 4,10-11, donde se refleja bien esta actitud universalista en el Antiguo Testamento).

Ni tampoco es, obviamente, un privilegio exclusivo de la Iglesia, pues, como dirá un discípulo de Pablo, "Dios quiere que todos los hombres se salven y lleguen al conocimiento pleno de la verdad" (1 Tim 2,4).

Más bien, los dones de Dios apuntan siempre a un servicio al mundo, a algo que, por ejemplo, ya Abraham deberá realizar, por encargo de Dios, a favor de los otros pueblos de la tierra. Eso es lo que le revela Dios a Abraham, cuando le promete no solo que tendrá una gran descendencia, sino que en él serán bendecidos todos los pueblos de la tierra ( $c f r$. Gn 12,1-3). La elección por parte de Dios, por lo tanto, es para poder realizar una misión en nombre de Dios. Pues en la Biblia, todo don de Dios se convierte automáticamente en tarea de cara al mundo, al que Dios ama y quiere transformar, salvar, con la ayuda del pueblo de Dios.

Esta prioridad del don gratuito de Dios es lo que Pablo denomina, con una formulación para nosotros hoy un poco difícil, pero que expresa algo fundamental para la fe de Pablo, la "justificación por la fe" (cfr. Rom 1,16-17; 3,21-26). Con ella, Pablo quiere que sus comunidades hagan una cura de humildad. Y lo hace destacando el hecho de que el formar parte del pueblo de Dios jamás es la consecuencia de los méritos o de la cualidades que se tienen. Más bien, quiere ser signo del poder creador del amor de Dios, que nos capacita para ser signo e instrumento de ese amor. Por esa razón, siempre mantiene su estructura fundamental de gratuidad cuando anima, llama, a los seres humanos a ser instrumentos de su amor en el mundo ${ }^{18}$.

Pasar a formar parte del pueblo de Dios, por lo tanto, es algo que brota de una iniciativa totalmente gratuita de Dios, que escoge a unas personas determinadas,

18. Estas ideas las desarrollo más ampliamente en mi comentario a la Carta a los Romanos, o. c., pp. 51-71. Cfr. también el capítulo "Espiritualidad bíblica y lucha por la justicia", en X. Alegre, Al acecho del reino diferente. Temas bíblicos básicos en clave liberadora, pp. 17-49 (Madrid, 2012). 
sin mérito alguno de su parte, para que revelen a todo el mundo la universalidad y la gratuidad del amor de Dios a toda la humanidad.

Nunca, por lo tanto, insisto en ello porque es fundamental, es un privilegio que se haya recibido por méritos propios y que pueda dar una prerrogativa frente a los demás. Ya vimos que fue así en el Antiguo Testamento ( $c f r$. Dt 7,6-11). Por ello, no es casual que Dios empiece la historia liberadora de la salvación escogiendo a Abraham y lo convierta en un emigrante. Y también es significativo que el pueblo escogido, Israel, no sea un pueblo poderoso, un imperio, sino un pueblo oprimido, esclavizado en Egipto, razón por la cual Dios lo quiere liberar, para que tomemos conciencia de que Dios no quiere la opresión de nadie ( $c f r$. Ex 3).

Esta idea fundamental de que el amor de Dios es siempre gratuito - y para mostrarlo, escoge, contra la lógica de este mundo, no a los fuertes y poderosos, sino a los débiles y oprimidos-, la recuerda también Pablo, cuando escribe a su comunidad de Corinto, amenazada por las divisiones internas. Por eso, le señala que la Iglesia no está formada, precisamente, por aquellas personas consideradas como fuertes y valiosas por la lógica de este mundo ( $c f r$. 1 Cor 1,10-16.26-31), sino por gente en su mayoría sencilla y pobre ( $c f r$. también lo que dijo Jesús, según Mt 11,25-30). En la lógica de Dios, y es importante que la Iglesia lo revele en su modo de funcionar, "la necedad divina es más sabia que la sabiduría de los hombres, y la debilidad divina, más fuerte que la fuerza de los hombres" (1 Cor 1,25; cfr. 1,17-24, donde Pablo habla del significado de la cruz). Es por eso que todo cristiano, incluido el apóstol, sabe, tal como subraya Pablo, que, tenga el don que tenga, lleva ese don en "vasos de barro para que aparezca que una fuerza tan extraordinaria es de Dios y no de nosotros" (2 Cor 4,7).

Pero demos ahora un paso más. Preguntémonos en qué consiste específicamente la misión que Dios confía a la Iglesia y qué papel desempeñan el laico y la laica en dicha misión.

\subsection{La misión del laico: seguir a Jesús}

Si algo debe distinguir a una persona cristiana, según el Nuevo Testamento, es el seguimiento de Jesús. Ya el primer evangelista, Marcos, enmarca todo su relato de lo que Jesús hizo y dijo en una llamada fundamental a seguir a Jesús ( $c f r$. Mc 1,16-20 con 16,7). Un seguimiento que, cuando es coherente y radical, fácilmente puede llevar a la cruz ( $c f r$. Mc 8,34), siguiendo las huellas del Maestro (cfr. Mc 8,31). Marcos es seguido por todos los sinópticos, que también enmarcan la vida y la actividad de Jesús en el llamado al seguimiento ( $c f r$. Mt 3,12-17 con 18,16-20; Lc 5,1-11 con 24,36-49). Juan también procede de la misma manera (cfr. Jn 1,35-51 con 20,19-29 y 21,1-23).

De modo especial quisiera fijarme en Mateo, que pone en boca de Jesús resucitado las siguientes palabras, que indican cómo quiere que la Iglesia, 
representada por sus discípulos, continúe en la tierra el proyecto del reinado de Dios, iniciado por él ( $c f r$. Mt 4,23; 5,3-10; 9,35; 10,7-8).

Me ha sido dado todo poder en el cielo y en la tierra. Vayan, pues, y conviertan en discípulos míos a todas las gentes bautizándolas en el nombre del Padre y del Hijo y del Espíritu Santo, y enseñándoles a guardar todo lo que yo les he enseñado. Y he aquí que yo estoy con ustedes todos los días hasta el fin del mundo (Mt 28,18-20).

La tarea esencial de la Iglesia, por lo tanto, es procurar que toda persona se incorpore a Cristo por el bautismo, como diría san Pablo ( $c f r$. Rom 6). Pero el bautismo solo puede desplegar toda su dinámica y plenitud en la medida en que el creyente se convierta en discípulo auténtico de Jesús y vaya integrando, en su modo de pensar y de vivir, todo lo que Jesús enseñó durante su vida pública y que Mateo recoge en su evangelio. El núcleo fundamental de esta enseñanza de Jesús la formula Mateo, de modo programático, en el sermón del monte, en Galilea ( $c f r$. Mt 5-7). Y eso es lo que ahora es recordado explícitamente por el Resucitado, al aparecerse en un monte de Galilea, al final del evangelio ( $c f r$. Mt $28,16)$. $\mathrm{Y}$ en eso no hay ninguna diferencia entre las personas cristianas, sean estas laicas, religiosas o participen del sacerdocio sacramental.

Pero en la Iglesia, la invitación a participar del proyecto de Jesús no es tanto individual como comunitaria. En un mundo marcado por la injusticia y la exclusión de las mayorías empobrecidas, el proyecto de Jesús solo puede ser vivido y llevado a cabo de modo adecuado en comunidad como Iglesia. Por eso, la misión de toda persona cristiana es fundamentalmente eclesial, lo cual no excluye que en dicho trabajo participe cualquiera que no forme parte de la Iglesia, mientras lo que haga esté en consonancia con lo que hizo Jesús ( $c f r$. Mc 9,38-40) y redunde en bien de la humanidad.

\subsection{La misión cristiana está integrada en la Iglesia}

El proyecto de Jesús es necesariamente "contracultural", porque se desarrolla en un mundo configurado por el egoísmo. Su proyecto, que denominaba reino de Dios, según la tradición del Antiguo Testamento ${ }^{19}$, no responde a la lógica de este mundo. Por eso, quiere que la misión eclesial de toda persona cristiana se desarrolle en el marco de la Iglesia, que, por su mismo modo de ser y de funcionar, transparente la lógica del reino sin enturbiarla.

19. Lo que entendía Jesús y lo que podían entender sus discípulos, que estaban anclados religiosamente en el Antiguo Testamento, por reino de Dios, lo desarrollo más, en X. Alegre, La palabra no está encadenada. Aproximaciones al Nuevo Testamento en clave liberadora, pp. 198-205 (San Salvador, 2009). 
Por eso, y dentro de ese modo "contracultural", escandaloso para la lógica de nuestro mundo, en el cual Jesús quiso hacer presente el reino de Dios ( $c f r$. Mc 8,31-33; 1 Cor 1,17-25), la Iglesia no debe fomentar en su seno estructuras patriarcales, separadoras, sino fomentar la fraternidad entre sus miembros ( $c f r$. Mt 23,9-12), pues, según Jesús, todos los cristianos y cristianas son, esencialmente, hermanos ${ }^{20}$, hermanas, iguales en dignidad aun cuando, como es obvio, no coincidan en la función que desempeñan.

En todo caso, independientemente de la función, nadie debe creerse superior a los demás. Ni apoyarse en la función que desempeña para dominarlos. Si algún distintivo es propio del cristiano, es el servicio y el servicio por amor. Este fue el sentido que Jesús dio a su vida, un sentido que contrapuso a las tentaciones de poder de sus discípulos ( $c f r$. Mc 10,35ss). Jesús formula concisamente el sentido de su venida a este mundo injusto, que quiso cambiar y que lo llevó a la cruz: "el Hijo del hombre no ha venido a ser servido, sino a servir y a dar su vida como rescate por todos" (Mc 10,45).

Y de eso les dio ejemplo en su cena de despedida, cuando se puso a lavar los pies de sus discípulos ( $c f r$. Jn 13,1-20). En este sentido, el papel de la persona laica en la Iglesia jamás debe ser secundario o de mero apoyo a los sacerdotes. Laicos, laicas, religiosos, religiosas y sacerdotes somos, ante todo, como ya señaló san Pablo, hablando del trabajo de los que edifican la comunidad ( $c f r .1$ Cor 3,9), cooperadores de Dios, en la construcción del reino, aunque, como es obvio, lo hemos de hacer con un espíritu humilde y de servicio, tal como nos lo mostró Jesús. Pero, en todo caso, todo cristiano, por el mero hecho de serlo, es "campo y edificación de Dios" (cfr. 1 Cor 3,9). Más aún, es "santuario de Dios", puesto que el Espíritu Santo habita en él (cfr. 1 Cor 3,16).

\subsection{Ser miembro del Cuerpo de Cristo: el marco de la misión}

Finalmente, quiero destacar una idea que es muy importante para Pablo, cuando quiere explicar lo que es la Iglesia y cómo debe funcionar en sus relaciones internas. Me refiero a la imagen del "cuerpo de Cristo", que Pablo utiliza con preferencia para hablar de ella ( $c f r$. 1 Cor 12-14 y Rom 12,3-8).

Cuando habla de los miembros de la Iglesia, Pablo subraya, en primer lugar, su unidad, semejante a la del cuerpo, pues sin ella no puede funcionar. El cuerpo es uno porque Cristo, que es el fundamento sobre el que se ha edificado la Iglesia, ( $c f r .1$ Cor 1,10-16), es también uno y no está dividido. La Iglesia jamás puede tener otro fundamento ( $c f r$. 1 Cor 3,11). Por ello y para mantener esta unidad, Jesús resucitado nos ha dado su Espíritu a todas las personas que formamos su

20. Así es como suele designar Pablo a los cristianos, inspirándose en el Antiguo Testamento; cfr. J. A. Estrada, La identidad, o. c., pp. 42-45. 
Iglesia ( $c f r$. Jn 14,15-17.25-26; 15,26-27; 16,12-14), que también es uno ( $c f r .1$ Cor 12,4). El Espíritu es el que está detrás de todo trabajo misionero, posibilitando así su eficacia para el reino. Por lo tanto, está detrás de cualquier cualidad, don o carisma ( $c f r .1$ Cor 12,4-11). Pablo siempre ve en todo lo que hacemos al Espíritu Santo, que nos da los dones que nos capacitan para el servicio. Siempre los da en función del bien común, para el provecho de la comunidad (cfr. 1 Cor 12,7).

Pablo no dice que la diversidad es mala en la Iglesia y que todos debamos hacer los mismo. Todo lo contrario. Cada miembro tiene su función. Y la riqueza del cuerpo y, por lo tanto, de la Iglesia, está precisamente en la diversidad de las funciones, y, por ende, de las misiones, que el Espíritu de Jesús ha confiado a cada uno de los miembros que formamos la Iglesia ( $c f r$. Rom 12,4-8).

En este contexto, por lo tanto, es esencial la cooperación de todos los miembros, sin que unos puedan considerarse superiores o con más privilegios que los otros. Ciertamente, las funciones son distintas y algunas son más significativas que otras dentro del cuerpo y por lo tanto, de la Iglesia, pero ningún miembro puede despreciar a otro y considerarse superior a él (cfr. 1 Cor 12,21-26). Todos formamos un solo cuerpo y en él no hay diferencia alguna fundamental entre "judíos y griegos, esclavos y libres", laicos y sacerdotes-religiosos, pues "todos hemos bebido de un solo Espíritu" (cfr. 1 Cor 12,13) y eso es lo esencial para toda vida cristiana, tanto si la persona es "laica", en el sentido moderno de la palabra, como si es sacerdote.

Esto nos ha ido quedando cada vez más claro en la Iglesia católica, a partir del Vaticano II, que implicó un cierto cambio de paradigma en la concepción de la Iglesia. El concilio ha procurado recuperar el espíritu de los inicios del cristianismo, superando el talante clerical que dificultaba la cooperación entre sacerdotes y laicos o laicas. Desde el segundo milenio, ese talante había clericalizado, "sacralizado" 21 , cada vez más la concepción y el funcionamiento de la Iglesia, separándose así de sus orígenes, que encontramos en el Nuevo Testamento. El "cambio de paradigma" eclesial ${ }^{22}$, puesto en marcha por el Vaticano II, influyó en los documentos de la Compañía de Jesús posteriores al concilio.

21. La sacralización progresiva del sacerdocio ministerial en la Iglesia católica lo desarrolla bien Estrada en su libro La identidad, o. c., pp. 81-107. En las pp. 109-152, muestra que ello tuvo su contrapartida en la manera, cada vez más alejada del Nuevo Testamento, como se fue viendo a los laicos.

22. El cambio de paradigma en la concepción del laico, que comenzó con el concilio Vaticano II, lo explica bien Estrada, en La identidad, o. c., pp. 153-187. Por eso, la Congregación General 34 proclama: "Una lectura de los signos de los tiempos a partir del Concilio Vaticano II muestra sin lugar a dudas que la Iglesia del siguiente milenio será la "Iglesia del laicado"' $(13,1)$. 


\section{Misión del laico, según las últimas congregaciones generales}

\subsection{Introducción}

Si lo que acabamos de ver es válido para cuestionar la separación entre laicos y sacerdotes, que se ha dado en la Iglesia desde finales del siglo II, es obvio que también debe tener consecuencias en la manera como los jesuitas deben colaborar con los laicos, en sus obras apostólicas.

La Compañía de Jesús ha aplicado a su modo de proceder la eclesiología derivada del Vaticano II $^{23}$. Aquí me fijaré cómo las dos últimas congregaciones generales (34 y 35) han tomado conciencia del cambio realizado en la Iglesia respecto a las relaciones entre los laicos y el denominado "orden sacerdotal" y los religiosos, representados en este caso por los jesuitas.

La relación entre jesuitas y laicos está configurada por algo que era propio de las iglesias del Nuevo Testamento, pero que antes del Vaticano II, sobre todo, a partir de la reforma gregoriana, había quedado bastante oscurecido en la Iglesia católica por culpa del clericalismo dominante. En efecto, el concilio intentó recuperar la igualdad propia de una Iglesia que no debe tener padres (Mt 23,9), sino que está configurada por relaciones de fraternidad y sororidad, aunque estas orientaciones conciliares se quedaron a medio camino en el postconcilio, por presiones de los conservadores. Pero ahora están siendo recuperadas por el papa Francisco.

\subsection{La aportación de las CG 34 y 35}

Muchos textos de los documentos finales de las congregaciones generales quieren expresar esta nueva realidad eclesial, que recupera el protagonismo fundamental de los laicos y las laicas en la Iglesia. Por lo tanto, se fijan en el trabajo que laicos y jesuitas debemos realizar en cooperación.

Los textos destacan que el laicado no tiene una función secundaria en la misión de la Iglesia y, consiguientemente, en la misión que realizan junto con los jesuitas. Al contrario, su misión es proclamada fundamental, sobre todo, en los tiempos actuales. Por eso, el n. ${ }^{\circ} 1$ del Decreto 13 de la Congregación General 34,

23. Con razón ha señalado Estrada que "[a]l mirar retrospectivamente hacia el concilio Vaticano II y analizar sus consecuencias para la vida de la Iglesia, aparece la doctrina conciliar sobre los laicos como el elemento quizá más relevante de la herencia conciliar. [...] Nunca en la historia de la Iglesia ha hablado un sínodo de forma más extensa, positiva y sistemática sobre la identidad, las funciones y el lugar que los seglares tienen en la Iglesia"; en La identidad, o. c., p. 7. También es significativa, en este sentido, Christifideles laici, de Juan Pablo II. Sobre las enseñanzas del concilio Vaticano II sobre los laicos, puede consultarse R. Pellitero (dir.), Los laicos en la eclesiología del Concilio Vaticano II. Santificar el mundo desde dentro (Madrid, 2006). 
Colaboración con los laicos en la misión, afirma explícitamente que la lectura de los signos de los tiempos, a partir del Vaticano II, lleva a pensar que la Iglesia del tercer milenio será "la Iglesia del laicado". Es signo de nuestros tiempos, aunque la jerarquía a menudo no se lo ha tomado suficientemente en serio, que cada vez un mayor número de laicas y de laicos ha respondido a la convocatoria a servir, un llamado que brota de su gracia bautismal. Y eso ha sido siempre una bendición para la Iglesia.

Por eso, el decreto afirma que la actualización de la vocación del laico en las variadas situaciones que le toca vivir ha llegado a ser la forma predominante como el pueblo de Dios sirve al mundo, en la promoción del reino (cfr. 34, 3, 1). La congregación subraya esta afirmación, citando a Juan Pablo II: "La Compañía de Jesús reconoce como una gracia de nuestro tiempo y una esperanza para el futuro el que los laicos 'tomen parte activa, consciente y responsable en la misión de la Iglesia en este decisivo momento de la historia" ${ }^{24}$.

Esta no es una novedad absoluta de la Compañía de Jesús, pues forma parte de la tradición más genuinamente ignaciana. En su tiempo, san Ignacio albergó a los que vivían sin techo en Roma, se preocupó por las prostitutas y estableció casas para huérfanos. Buscó colaboradores y con ellos estableció organizaciones y redes para continuar estos y muchos otros servicios $(35,6,30)$.

$\mathrm{Y}$ añade a continuación.

Para responder hoy a las acuciantes necesidades de nuestro complejo y frágil mundo, necesitamos sin duda muchas manos. La colaboración en la misión es nuestra respuesta a esta situación: expresa nuestra verdadera identidad como miembros de la Iglesia, la complementariedad de nuestras diversas vocaciones a la santidad, nuestra mutua responsabilidad por la misión de Cristo ${ }^{25}$, nuestro deseo de unirnos a las personas de buena voluntad en el servicio de la familia humana y la llegada del Reino de Dios. La colaboración es una gracia que se nos regala en este momento en perfecta coherencia con nuestro modo jesuita de proceder.

De esta "colaboración en misión" 26 , la Congregación General 34 saca la conclusión de que los jesuitas hemos de ir viendo cómo podemos concretar esta realidad eclesial para que no se quede en papel mojado. Y debemos hacerlo no desde arriba, como quien manda, sino desde el servicio sincero: "Deseamos responder a esta gracia poniéndonos al servicio de la plena realización de la misión de los laicos".

24. Juan Pablo II, Christifideles laici, 3.

25. 1 Cor 12,12 ss.

26. Sobre este tema, $c f r$. M. C. Luchetti Bingemer, "Jesuitas y laicos: hacia una colaboración en misión", Diakonia 29 (2005), 49-61. 


\subsection{Pautas para el servicio de los jesuitas a la misión de los laicos}

Si la misión de los laicos es tan importante, entonces la pregunta que debemos plantearnos los jesuitas es cómo podemos ponernos "al servicio de la misión de los laicos".

Parece obvio que ello significa, ante todo, valorar dicha misión sin considerar en absoluto que pueda ser inferior a la labor de un jesuita. No se trata, pues, de que los laicos ejerzan una función subordinada a los jesuitas. Al contrario, se trata de trabajar en equipo, de colaborar juntos. En consecuencia, el tipo de trabajo depende de las cualidades propias de cada persona. Esto vale también para la dirección de las obras, incluso de aquellas que son propias de la Compañía de Jesús, pues el carisma de la dirección no tiene por qué tenerlo necesariamente un jesuita. Por eso, la Congregación 34 constata como positivo que "[e]n algunas partes del mundo las obras de la Compañía dependen primariamente de los laicos para que ésta realice su misión" $(13,2)$. La Compañía de Jesús piensa, según los documentos de las congregaciones 34 y 35, que es bueno que haya sido así. Más aún, cree que conviene que siga siendo así (cfr., por ejemplo, 34, 13, 13).

El ideal, por lo tanto, en la colaboración para la misión común de los cristianos, laicos o jesuitas, es que cada función la asuma aquella persona, hombre o mujer ${ }^{27}$, jesuita o laico, creyente o no, que esté más capacitado para desempeñarla. Lo único que hay que garantizar, en todo caso, es un buen trabajo en equipo, algo para lo cual los jesuitas, y no solo los jesuitas, a menudo no hemos sido formados adecuadamente. Por lo tanto, conviene cuidar este punto en el futuro. Por eso, la Congregación $35(6,16)$ recomienda cuidar este aspecto en la formación de los jesuitas. En la misma línea, la Congregación 34 señala también que se debe fomentar un

... auténtico compañerismo de laicos y jesuitas, desde el que cada cual actuará de acuerdo con su propia vocación. Los laicos asumirán con todo derecho un papel de mayor responsabilidad y liderazgo en esas obras. La Compañía deberá apoyarlos en sus iniciativas mediante una formación ignaciana, inculcándoles los valores apostólicos jesuíticos y dando testimonio de vida sacerdotal y religiosa. Si nuestro servicio se hace más modesto, también

27. La mujer ha sido especialmente marginada en la Iglesia, sobre todo, antes del Vaticano II, pero también después. Por eso, la Congregación General 34 reconoce que en este campo, los jesuitas necesitamos la gracia de "convertirnos": "Hemos sido parte de una tradición civil y eclesial que ha ofendido a la mujer. Como muchos otros varones, tenemos tendencia a convencernos de que el problema no existe. Aun sin percatarnos, hemos sido cómplices de una forma de clericalismo que ha respaldado el dominio convencional del varón con una sanción presuntamente divina. Con esta declaración queremos reaccionar personal y corporativamente y hacer lo que podamos para cambiar esta lamentable situación" $(14,12)$. 
resultará más motivador y creativo, y más en consonancia con las gracias que hemos recibido $(34,13,20)$.

\subsection{Cuidar el "aire de familia" en la colaboración}

De todos modos, hay un aspecto fundamental, en mi opinión, para que la colaboración entre todos y todas, laicos y jesuitas, sea positiva. Conviene que la cooperación se desarrolle en un "aire de familia". Un aire de familia que vendría marcado por la espiritualidad de san Ignacio, tal como esta quedó encarnada en los Ejercicios espirituales y tal como fue actualizada por la Congregación General 32, siguiendo la inspiración del Vaticano II. Esta espiritualidad coincide con lo que hemos visto en el Nuevo Testamento, sobre la misión de todos los cristianos y cristianas, sin distinción. En este sentido, la Congregación 35 afirma lo siguiente:

El corazón de una obra ignaciana son los Ejercicios Espirituales de San Ignacio. De hecho, una obra puede ser llamada ignaciana siempre que actúe de una manera que sea la característica del carisma ignaciano: cuando intencionalmente busque a Dios en todas las cosas; cuando practique el discernimiento ignaciano; cuando se acerque a la realidad a través de un cuidadoso análisis del contexto, en diálogo con la experiencia, evaluado por medio de la reflexión, orientado a la acción y abierto siempre a la evaluación. Una obra de este tipo no necesariamente dependerá de la Compañía para su identidad ignaciana, aunque puede estar afiliada o asociada a ella a través de redes y otras estructuras $(6,9)$.

Sin duda, es bueno y enriquecedor que todo tipo de personas colaboremos juntos, respetándonos en nuestro modo de ser y de pensar. Pero si queremos que nuestro trabajo sea un auténtico trabajo en equipo, que redunde en beneficio de las personas a las que dedicamos nuestro servicio, creo que hay que cuidar de modo especial el "aire de familia" del cual hablaba antes y que, desde la Congregación 32, quedó formulado, de modo sucinto, en la opción por la fe y la justicia como algo inherente al carisma ignaciano de nuestros tiempos. A continuación, intentaré expresar qué quiero decir con ello.

1) Al hablar de la opción por la fe y la justicia ( $c f r$. CG 32), no quiero decir con ello que la $f e$ cristiana tiene que ser compartida por todas las personas que colaboramos en una tarea, aunque sí ha de ser respetada, por lo menos - como los que compartimos la fe cristiana hemos de respetar las opciones de los demás, mientras puedan ser consideradas auténticamente humanas y humanizadoras.

2) En cambio, la opción por la justicia nos ha de unir a todas y a todos. Se trata, en todo caso, de que en nuestro trabajo en equipo seamos personas "que intentan construir un mundo de verdad, justicia, libertad, paz y amor" $(34,13,3)$.

En la misma línea de los documentos de las congregaciones generales, pienso que la opción por la fe no tiene por qué ser explícita en las personas con 
las cuales formemos equipo, pues la fe es algo que no tiene por qué ser común a todos. Dios la da, gratuitamente, no como mérito, sino como servicio, como hemos visto en la primera parte, para ir revelando cómo es él y cuál es la misión que confía, aunque no de modo exclusivo, a las personas creyentes.

En cambio, la opción preferencial por el pobre, por el excluido, por las mayorías empobrecidas de nuestro mundo, más aún, excluidas, es la clave para discernir si un creyente, lo sepa o no, es fiel al proyecto que Jesús vino a encarnar en el mundo ( $c f r$. Mt 25,31-46; también 1 Jn 3,11-24). Se trata, por lo tanto, de algo que, a mi juicio, un jesuita no puede marginar en su trabajo, ni tampoco en su trabajo en colaboración con personas que no sean jesuitas, porque es inherente y esencial a la fe cristiana.

Pero se trata de algo que también debería ser significativo e ineludible para un laico, sea creyente o no, pues en un mundo tan escandalosamente injusto como el nuestro, donde el uno por ciento de las personas más ricas posee tanto como el 88 por ciento más pobre, y en el cual cada día mueren de hambre miles de personas y muchísimas son víctimas de todo tipo violencia, la opción por la justicia, priorizando a los pobres, que son los que tienen la vida más amenazada, forma parte de una ética de mínimos, que debería ser común a todas las personas creyentes y no creyentes, simplemente por el hecho de ser seres humanos.

3) Hay otro aspecto que debería formar parte del "aire de familia", que posibilita una buena cooperación entre laicos y jesuitas. Se trata de algo que, en principio, es propio, pero no exclusivo, de la misión encomendada a toda persona cristiana, haya hecho la opción de vida que haya hecho. Es algo que la Congregación 34 afirma de los jesuitas, pero que, en aras de un buen trabajo en equipo, también debería ser propio de laicos y laicas, supuesto que unos y otras queremos trabajar juntos.

Los jesuitas somos, a la vez, "hombres para los demás" y "hombres con los demás" 28 . Esta característica esencial de nuestra forma de proceder pide prontitud para cooperar, escuchar y aprender de otros y para compartir nuestra herencia espiritual y apostólica $(34,13,4)$.

4) El cuarto aspecto no debe ser una condición imprescindible para la colaboración entre los laicos y laicas y los jesuitas, pero es muy positivo, cuando se da. El talante y la espiritualidad de los jesuitas están marcados por la experiencia cristiana, condensada en los Ejercicios espirituales. Por lo tanto, la cooperación entre laicos y jesuitas puede ser mucho más enriquecedora si se comparte la vocación cristiana, que es siempre un llamado a la misión, como vimos en la

28. P. H. Kolvenbach, A los amigos y colaboradores de la Compañía de Jesús, AR 20 (1991), 602. 
primera parte. Por eso, la Congregación 34 ve positivo que en lugares bien diversos,

... muchos hombres y mujeres dan testimonio del Evangelio. Los laicos están asumiendo mayor responsabilidad en los ministerios de la Iglesia allá donde viven, participan en el culto y trabajan. Llamados a la santidad y al compromiso por la fe, la justicia y los pobres, evangelizan las estructuras de la sociedad $(34,13,6)$.

Pero eso nos lleva a preguntarnos qué implicaciones tiene esto último para la colaboración entre los jesuitas y los laicos. Y luego, en segundo lugar, qué pueden ofrecer los laicos a los jesuitas.

\section{5. ¿Qué pueden ofrecer los jesuitas a los laicos, para su misión?}

Dado el papel primordial que el laico y la laica desempeñan, y han de desempeñar, en la Iglesia del siglo XXI, la Congregación 34 recuerda a los jesuitas que

... ponernos al servicio del apostolado de los laicos es para nosotros un reto. Necesitamos responder a su deseo de formación de suerte que sean capaces de servir más plenamente conforme a su vocación y a sus talentos. Esa formación debería aprovechar los numerosos recursos y experiencias de la Compañía. Cuando lo solicitan, no deberíamos dudar en ofrecerles la experiencia de los Ejercicios Espirituales y nuestra dirección espiritual. Podemos animarlos a asumir la prioridad apostólica del servicio de la fe y la promoción de la justicia con un amor preferencial por los pobres. Respondiendo de esta forma, les ofrecemos lo que somos. Como hombres dedicados a amar y servir a Dios en todas las cosas, deberíamos ayudar a otros a reconocer y discernir las posibilidades apostólicas de su vida y trabajo. Los laicos que colaboran en apostolados de la Compañía pueden esperar de nosotros una formación específica en los valores ignacianos y una ayuda en el discernimiento de los objetivos y prioridades apostólicas y de las estrategias prácticas para su realización $(34,13,8)$.

Y poco antes, había afirmado que los jesuitas ofrecemos

... lo que somos y hemos recibido: nuestra herencia espiritual y apostólica, nuestros recursos educativos y nuestra amistad. Ofrecemos la espiritualidad ignaciana como un don específico para la animación del ministerio laical. Esta espiritualidad apostólica respeta la espiritualidad propia del individuo y se adapta a las necesidades presentes; ayuda a las personas a discernir su vocación y "a amar y servir a la divina Majestad en todas las cosas" 29 . Ofrecemos a los laicos la sabiduría práctica que hemos aprendido en más de cuatro siglos de experiencia apostólica. Por medio de nuestras escuelas,

29. $E E[233]$. 
universidades y otros programas educativos ponemos a su disposición la formación pastoral y teológica. Lo que es quizá más importante, nos unimos a ellos para ser compañeros: sirviendo juntos, aprendiendo unos de otros, respondiendo a las mutuas preocupaciones e iniciativas y dialogando sobre los objetivos apostólicos $(34,13,7)$.

\section{6. ¿Qué pueden ofrecer los laicos a los jesuitas?}

Entre otras muchas cosas, los laicos y las laicas pueden ayudar a los jesuitas a ser más conscientes de la igualdad, esencial al cristianismo, entre todos y todas, en el servicio del reino. De esa manera, los jesuitas aprenderemos también de su testimonio y podremos así vivir mejor nuestra propia vocación. Es lo que señala la Congregación 35:

Compartir la misión con colaboradores nos anima a vivir más completa y auténticamente nuestra vocación religiosa de jesuita. [...] En la colaboración con otros, en el diálogo respetuoso y la reflexión compartida, en la acción junto a quienes viven un compromiso semejante, aunque realizado por un camino diferente, llegamos a conocer mejor nuestro propio camino y a vivirlo con nuevo celo y nueva comprensión $(35,6,15)$.

En especial, los colaboradores laicos nos pueden ayudar a reconocer y a valorar todo lo que aportan, de manera distinta a la nuestra, pero tan importante como ella, a la construcción del reino, del cual ellos son instrumentos imprescindibles. Esa experiencia es la que lleva a la Congregación 35 a declarar lo siguiente:

Estamos humildemente agradecidos de que muchos -inspirados como nosotros por la vocación de Ignacio y la tradición de la Compañía- hayan elegido trabajar con nosotros y compartir nuestro sentido de misión y nuestra pasión por salir al encuentro de los hombres y mujeres de nuestro mundo roto, pero digno de ser amado. Hemos sido enriquecidos no sólo por personas que comparten nuestra misma fe, sino también de otras tradiciones religiosas y por mujeres y hombres de buena voluntad de todas las naciones y culturas con quienes luchamos buscando un mundo más justo. Rica es la cosecha. En muchos países, obras jesuitas importantes dependen en buena medida de la colaboración generosa, leal y competente de mujeres y hombres de diversas convicciones religiosas y humanistas. Cuando el Santo Padre confirma nuestro ministerio y vocación y nos dice "la Iglesia os necesita", debemos responder mirando a nuestros colaboradores en la misión y decir, con gratitud y profundo afecto, que la vocación que hemos recibido es una vocación conjuntamente compartida con ellos $(35,6,3)$. 


\section{Conclusión: recuperación del significado de los laicos en la Iglesia}

\subsection{El legado del Nuevo Testamento y de los signos de los tiempos}

El Nuevo Testamento, el concilio Vaticano $\mathrm{II}^{30}$, releído a la luz de Medellín y Puebla ${ }^{31}$, el mensaje y testimonio de Mons. Romero y de tantos mártires, de tantas personas que dieron su vida intentando encarnar el proyecto de Jesús, así como las últimas congregaciones generales de los jesuitas, nos ayudan a ver con más claridad la misión del laico y de la laica en la Iglesia.

Pero también la manera concreta como jesuitas y laicos podemos y debemos actualizar nuestra misión, por fidelidad al Evangelio de Jesús, modelo preclaro para el laico y para el religioso.

Recuperar la visión del Nuevo Testamento, actualizada por el concilio Vaticano II, es algo, sin duda, muy positivo, pero a la vez un reto difícil para todas y todos nosotros, sobre todo, si fuimos formados en la teología preconciliar. Recuperar el protagonismo de las y los laicos en el pueblo de Dios no será una tarea fácil, en una Iglesia tan clericalizada como la católica. Pero no hay motivos para desanimarse o para perder la esperanza, pues, como dice Jesús en el Apocalipsis a la Iglesia de Laodicea, y a través de ella a todas las iglesias, "yo, a los que amo, reprendo y corrijo" $(3,19)$. Podemos confiar en que la acción de Jesús será eficaz, pues, como dice Efesios 5,25, "Cristo amó a la Iglesia y se entregó a sí mismo por ella", prometiendo que siempre estaría con ella hasta el fin de los tiempos (Mt 28,20). Y como Cristo participa del poder de Dios y sabemos que "para Dios todo es posible" (Mc 10,27), nuestra esperanza en la renovación de la Iglesia tiene fundamento. La actuación del papa Francisco es un buen signo, que confirma esa esperanza.

\subsection{Valoración y promoción del laicado, según las CG 34 y 35}

Las orientaciones de las congregaciones generales 34 y 35 se encuentran en la línea neotestamentaria de valoración y promoción del laicado. Por eso, la Congregación 35 declara que los jesuitas

... necesitamos desplazar cada vez más el centro de nuestra atención del ejercicio de nuestro propio apostolado directo a la potenciación del laicado en su misión. El hacerlo requerirá de nosotros habilidad para utilizar los talentos de los laicos, animarles e inspirarles. Nuestra prontitud para afrontar este

30. "El proceso iniciado con el Concilio no se detuvo por ahí. En el año 1987, el Sínodo sobre los laicos y el documento que a él siguió, la exhortación pos-sinodal Christifideles Laici, reiteran las afirmación del Concilio y dan algunos pasos más, reafirmando la importancia del llamado a la santidad hecho a todos los cristianos por el Bautismo" (M. Luchetti Bingemer, o. c., pp. 51s.).

31. Cfr. ibid., pp. 52s. 
reto dependerá de la consistencia de nuestro sentido de "compañeros" y de la renovación de nuestra respuesta a la vocación misionera de Cristo $(35,13,19)$.

En este sentido, es muy importante que los jesuitas aprendamos a colaborar y a no querer tener siempre el protagonismo.

Todos los colaboradores en la obra [de la Compañía] deberían ejercer la corresponsabilidad y comprometerse en el proceso de discernimiento y toma de decisiones compartida, cuando sea oportuno. Los laicos, según sus capacidades y compromiso, deben acceder a cargos de responsabilidad y prepararse para ello $(34,13,13)$.

En esa misma línea, la Congregación 35 declara:

Del mismo modo, la importancia de la colaboración en la misión implica que todos los jesuitas, como hombres en misión, debemos ser también hombres de colaboración. La promoción permanente en esta área debe ser animada y apoyada en las provincias y por las Conferencias Jesuitas. Los programas de desarrollo profesional y crecimiento espiritual, cuando se emprenden junto con los colaboradores, pueden contribuir a profundizar en el sentido de una visión común y en la unidad de la misión $(35,6,17)$.

Esto es válido no solo para la colaboración entre laicos y jesuitas en las instituciones llevadas por la Compañía de Jesús, sino también para la colaboración con cualquier institución u organización.

Nuestra misión actual nos pide también una cooperación más estrecha con instituciones, organizaciones y actividades no patrocinadas por la Compañía [...] Tal cooperación es una forma de dar testimonio del Evangelio y de la espiritualidad ignaciana y nos permite entrar en ambientes donde la Iglesia desea estar presente. Este tipo de colaboración nos permite expresar nuestra solidaridad con los demás y al mismo tiempo aprender de ellos de un modo enriquecedor para la Compañía y la Iglesia $(34,13,14)$.

\subsection{Importancia de una buena formación}

En este campo relativamente novedoso de la colaboración, todos, jesuitas y laicos, hemos de aprender y buscar una buena formación, que nos capacite para ella. La formación es decisiva para poder responder, lúcidamente, a las nuevas demandas de los signos de los tiempos.

Por todo el mundo se han desarrollado numerosos programas de formación ignaciana, adaptados a diversos contextos culturales y religiosos. La gracia fundacional de los Ejercicios Espirituales está cada vez al alcance de más gente y nos da a todos un lenguaje y una experiencia comunes que sirven como raíz e inspiración para la colaboración en la misión. Un número creciente de obras jesuitas son dirigidas por laicos comprometidos, por reli- 
giosos o por sacerdotes diocesanos. Los miembros de la Compañía -sacerdotes y hermanos, jesuitas formados y jesuitas en formación - poseemos una mayor conciencia de la responsabilidad compartida con otros en la misión y ministerio de la Compañía. Más aún, la Compañía se ha enriquecido a través del encuentro con comunidades de diálogo y de cooperación. Laicos y religiosos, mujeres y hombres, indígenas y personas con diferentes experiencias religiosas y espirituales: todos ellos nos han cambiado y han alimentado en nosotros un mayor sentido de Dios, en quien "vivimos, nos movemos y existimos" ${ }^{32}$. La gracia de estos años se refleja en una más extensa y profunda colaboración apostólica, que nos pone a todos - a los jesuitas y a los otroscon el Hijo $(35,6,5)$.

Esa formación es decisiva no solo para los jesuitas, sino también para las laicas y los laicos.

Sin embargo, la formación de jesuitas para la colaboración debe acompañarse con una formación paralela para aquellos con los que colaboramos en el servicio, de modo que todos puedan profundizar en el conocimiento de la misión compartida. Diversos programas, que respetan e incorporan la sabiduría y experiencia de los que participan en ellos, permiten una apropiación personal de la misión de la Compañía. Respetando los distintos niveles de relación y comprensión, estos programas invitan a cada persona - sea empleado o voluntario, recién llegado o asociado desde hace tiempo, cristiano, miembro de otra comunidad de fe, no creyente- a una mayor conciencia de su lugar en la misión ignaciana y jesuita $(35,6,18)$.

\subsection{Cuestiones a resolver}

Esta colaboración en la misión plantea una serie de cuestiones que hay que ir dilucidando a lo largo de nuestro trabajo en equipo, laicos y jesuitas. El Decreto 6 (n. ${ }^{\circ}$ ) de la Congregación 35 plantea tres cuestiones: (a) ¿Qué hace que una obra sea jesuita y cómo puede ser sostenida por un liderazgo no jesuita?; (b) ¿cuáles son los elementos de formación necesarios para los jesuitas y los otros, a fin de asegurar el crecimiento en el espíritu y en la práctica de nuestra misión?; y (c) ¿qué vínculos pueden unirnos como colaboradores en la misión, que buscan servir juntos, con afecto profundo, en la tarea encomendada a la Compañía?

El mismo decreto da algunas pistas para resolver estas cuestiones:

Una obra ignaciana se puede llamar jesuítica cuando tiene una clara y definida relación con la Compañía de Jesús y cuando su misión concuerda con la de la Compañía, por un compromiso con la fe que realiza la justicia por medio del diálogo interreligioso y una responsabilidad creativa con la cultura. En tal

32. Hch 17,28. 
contexto la misión de la obra, dirigida por un jesuita u otra persona que comparta este compromiso, está "en último término bajo la autoridad del General de la Compañía a través de los diversos cargos intermedios" ${ }^{33}(35,6,10)$.

El liderazgo de una obra jesuita depende del compromiso con la misión y puede ser ejercido por jesuitas o por otros. Dichos directivos deben estar comprometidos con la misión de la Compañía tal como se concreta en la obra particular, aunque pertenezcan a tradiciones espirituales o religiosas distintas de la nuestra. La claridad acerca de la misión de cada obra apostólica y el papel propio de cada uno de sus componentes evitan malentendidos, promueven mayores posibilidades de evaluación y desarrollan trabajo en equipo $(35,6,11)$.

En el desarrollo de una relación entre la Compañía y una obra jesuita es de vital importancia que los Superiores Mayores consideren y apoyen a quienes están en cargos directivos, jesuitas u otros. Un diálogo regular, llevado en un espíritu de confianza y respetando la adecuada subsidiariedad, favorece el discernimiento, la responsabilidad y un sentido más claro de colaboración en la misión. Además, el Provincial, u otro en su lugar, debe compartir con estos directivos información importante y directrices de la Compañía universal, animando a una visión más amplia de la misión y a una mejor comprensión de las prioridades y de los criterios apostólicos $(35,6,12)$.

\subsection{Importancia del trabajo en red}

A todas estas recomendaciones, que son fundamentales, hay que añadir una que tiene especial relevancia en el mundo actual. Me refiero a la importancia del trabajo en red.

La Congregación General 34 invitó a la Compañía a desarrollar una "red apostólica ignaciana" 34 entre personas y asociaciones que compartieran un compromiso ignaciano de servicio en la Iglesia. En aquellos lugares en que la Compañía ha respondido con celo a esta invitación está creciendo la cooperación en programas de formación, así como en el discernimiento, planificación y ejecución de proyectos comunes. Estas redes capacitan a mujeres y hombres con preocupaciones comunes a compartir sus experiencias y aprovechar sus respectivas competencias. De este modo se hacen realidad las siempre crecientes posibilidades del trabajo en red. Más aún, cuando la tradición ignaciana es expresada por voces diversas - mujeres y hombres, religiosos y laicos, movimientos e instituciones, comunidades e individuos - se hace más aceptable y más vigorosa, capaz de enriquecer a toda la Iglesia $(35,6,23)$.

33. Orientaciones para las relaciones entre el superior y el director de obra, AR 22 (1996-2002), 415; Instrucción sobre Administración de bienes, 109-111.

34. CG 34, 13, 21. 
En la medida en que se desarrollan los instrumentos de comunicación, la Compañía trabaja más efectivamente como cuerpo internacional y busca sinergias al servicio de una misión universal. Los jesuitas se encuentran a menudo involucrados, más allá de los límites de su provincia, en redes nacionales e internacionales, en colaboración con diversas personas, incluyendo otros jesuitas. Algunas de estas redes internacionales, como el Servicio Jesuita a Refugiados, Fe y Alegría y la Red Jesuita Africana contra el Sida son obras de la Compañía. Otras son proyectos compartidos. En todos estos trabajos el bien que se consigue se multiplica gracias a la participación de la Compañía en colaboración con grupos diversos unidos en una misión común $(35,6,22)$.

\subsection{El testimonio de Mons. Romero}

No quiero terminar sin citar un texto de Mons. Romero referido a la Rerum novarum, dado que he escrito este artículo en San Salvador, un año después de la beatificación del arzobispo. Mons. Romero siempre se destacó por su amor, aprecio y promoción no clerical de los laicos y las laicas, pues estaba convencido, como dijo en una ocasión, de que "con este pueblo, no cuesta ser pastor". Por eso dijo, el 13 de noviembre de 1977:

Es gloria de la Iglesia estar presente promoviendo. Y precisamente porque promueve, se le critica y se le calumnia y se mal informa. Pero, hermanos, me da mucho gusto pertenecer a esta Iglesia que está despertando la conciencia del campesino, del obrero, no para hacerlo subversivo - ya hemos dicho que la violencia pecadora no es buena-, sino para que sepa ser sujeto de su propio destino, que no sea más una masa dormida; que sean hombres que sepan pensar, que sepan exigir.

Cuando a Jesús le preguntaron con qué criterios había que medir el valor de lo que uno hacía, dio uno fundamental: "Por sus frutos, los conocerán" (Mt 7,16.20). Confiemos, pues, en que las pistas que el Nuevo Testamento, el concilio Vaticano II, Mons. Romero y las congregaciones generales 34 y 35 nos ofrecen, contribuyan, de manera eficaz, a que este siglo sea, como se ha dicho, el siglo de las y los laicos en la Iglesia. De esa manera, el impulso eclesial de Jesús, que, como laico, hizo un auténtico servicio sacerdotal a la humanidad ( $c f r$. Hebreos), irá tomando cada vez más cuerpo en la Iglesia, de acuerdo con lo que nos piden los signos de los tiempos. 